\title{
Participação Feminina na Empresa Júnior de Computação - CJR da Universidade de Brasília
}

\author{
Alice Borges ${ }^{1}$, Fernanda de Sousa ${ }^{1}$, Maristela Holanda ${ }^{1}$, \\ Aleteia P. F. Araujo ${ }^{1}$, Carla Cavalcante Koike ${ }^{1}$, Roberta B. Oliveira ${ }^{1}$ \\ ${ }^{1}$ Departamento de Ciência da Computação - Universidade de Brasília (UnB) \\ Brasília - DF - Brasil \\ \{alice.borges, fernanda.macedo\}@aluno.unb.br \\ \{mholanda, aleteia, ckoike, roberta.oliveira\}@unb.br
}

\begin{abstract}
Women are underrepresented in the Computing area. This is an issue not only in Brazil, but it is reflected in different countries around the world. The lack of gender diversity is present in higher education in Brazil, and also in the labor market. The Junior Companies Movement is an initiative that allows undergraduate students to enter the job market during their time at university. In this context, this paper presents an analysis of female participation in CJR, a junior company in the Department of Computer Science of University of Brasilia $(U n B)$, and describes initiatives to increase the number of female students in the company. These initiatives include a selection recruitment process with the theme of princesses, and with the interviews carried out by women. Following these actions $50 \%$ of the leadership roles were assumed by women, and the number of female undergraduate students went from $2 \%$ in 2018, to $16 \%$ in 2020.
\end{abstract}

Resumo. Mulheres têm pouca inserção na área de Computação. Este é um problema não apenas no Brasil, mas também em diferentes países do mundo. A falta de diversidade de gênero em cursos de Computação no ensino superior no Brasil é reportada em diferentes artigos, e isso reflete diretamente no mercado de trabalho. Uma iniciativa que tem levado os estudantes universitários a inserir-se no mercado de trabalho durante a universidade é o movimento de empresas juniores. Neste contexto, este artigo apresenta uma análise da participação feminina na CJR, uma empresa júnior do Departamento de Ciência da Computação da Universidade de Brasília (UnB). Além de descrever ações para aumentar a representativa feminina na empresa, como ação para seleção com tema de princesas e o processo de seleção ser realizado por mulheres. Após essas ações os resultados foram que a parte de liderança da empresa á ocupada por $50 \%$ de mulheres e o número de alunas passou de $2 \%$ em 2018, para $16 \%$ em 2020.

\section{Introdução}

A falta de diversidade de gênero na Computação tem sido bem retratada na literatura, como pode ser visto em [Ribeiro et al. 2019] com dados da Sociedade Brasileira da Computação, onde entre os associados, que tem estudantes, professores, pesquisadores 
e profissionais, em 2018, 78,13\% eram de homens, e apenas $21,87 \%$ de registros de mulheres. Esta falta de diversidade de gênero na Computação aparece também no mercado de trabalho, onde, no Brasil o número de mulheres em empresas de tecnologia é de $22 \%$, e apenas 6\% estão em cargos de liderança [Rosario 2021].

Mundialmente, o problema de diversidade de gênero no mercado de trabalho de tecnologia vem sendo reportado, como por exemplo, a empresa Facebook aprensenta relatórios anuais sobre a diversidade de gênero, raça/etnia entre seus funcionários. Especificamente, em relação a questão de gênero, no Facebook em seu relatório de diversidade em 2020 entre os seus empreados, 24\% eram mulheres que trabalham na área de tecnologia [Facebook 2020]. De maneira semelhante, a empresa Google também tem relatórios de diversidade entre seus funcionários, e em 2020, apresentou que apenas $28,1 \%$ de seus funcionários eram mulheres na área de tecnologia [Google 2020].

A falta de mulheres no mercado de trabalho de Computação implica no desenvolvimento da tecnologia sendo criada por um grupo relativamente homogêneo de trabalhadores do sexo masculino. Esse padrão é especialmente preocupante, dada a evidência dos benefícios críticos que a diversidade traz para a inovação, resolução de problemas e criatividade [Ashcraft et al. 2016]. Neste sentido, é de fundamental importância iniciativas que tenham o objetivo de incluir mais mulheres no mercado de trabalho.

O Movimento Empresa Júnior (MEJ) teve início na França com o surgimento da primeira Empresa Júnior, em 1967 [Lanzillotti et al. 2004] com o objetivo de permitir a vivência em uma realidade empresarial, antes mesmo da formação do aluno. Neste sentido, os estudantes das universidades brasileiras têm trabalhado na integração da graduação com o mercado de trabalho, por meio da participação nesse movimento [Pinheiro et al. 2019]. De acordo com o Artigo $2^{\circ}$ do Conceito Nacional de Empresa Júnior [Júnior 2004], uma empresa júnior deverá estar registrada perante a Receita Federal e órgãos governamentais como uma pessoa jurídica, de direito privado, associação civil sem finalidades econômicas e com fins educacionais. Entre seus objetivos, de acordo com o Artigo $7^{\circ}$ está, promover contato dos alunos com o mercado de trabalho. Dessa forma, uma empresa júnior é uma empresa criada e gerenciada por alunos de graduação de instituições de ensino superior, proporcionando capacitação por meio de experiências reais.

Neste contexto, este artigo tem como objetivo apresentar a Empresa Júnior da Universidade de Brasília do Departamento de Ciência da Computação com uma visão de gênero, descrevendo a participação das alunas em diferentes cargos, assim como, apresenta as ações para incluir mais meninas nessa empresa. $\mathrm{O}$ diferencial deste artigo é que apesar de existir várias publicações sobre a participação feminina nas universidades, atividades para inclusão de meninas no ensino fundamental e médio, existe uma falta de informação sobre a atuação das mulheres nas empresas juniores da área de Computação.

Este artigo está dividido em mais 5 seções. A Seção 2 apresenta um relato do histórico da Empresa Júnior de Computação - CJR; na Seção 3 um retrato da representatividade de mulheres na CJR é descrito, assim também, como elas estão em relação aos cargos de liderança. A Seção 4 apresenta as atividades realizadas para o incentivo e a inclusão de mais meninas na empresa; na Seção 5 são apresentados depoimentos de 6 alunas que fizeram parte da empresa júnior. Por fim, as conclusões e trabalhos futuros são 
desatidas na Seção 6.

\section{A CJR da Universidade de Brasília}

O Movimento Empresa Júnior no Brasil tem como missão "Formar, por meio da vivência empresarial, empreendedores comprometidos e capazes de transformar o Brasil" [Júnior 2019a]. Este movimento tem como propósito promover o desenvolvimento técnico e acadêmico de seus associados, proporcionando aos alunos contato com o mercado de trabalho, incentivando assim, sua evolução profissional e pessoal [Júnior 2004]. Assim como, promove o desenvolvimento econômico da comunidade, por meio de suas atividades, e fomenta o espírito empreendedor em seus associados.

A CJR é uma empresa júnior fundada em 23 de outubro de 1999 por alunos do curso de graduação em Ciência da Computação da UnB. Originalmente, composta pelos alunos dos cursos de Bacharelado em Ciência da Computação e Licenciatura em Computação mas, a partir de 2017 passou a incluir também os graduandos do curso Engenharia de Computação. Nos útlimos 3 anos a CJR desenvolveu vários projetos e o seu faturamento é detalhado na próxima seção.

\subsection{Influência da CJR no Mercado}

No ano de 2018 foram realizados 20 projetos, totalizando um faturamento anual de R $\$$ $52.000,00$, já no ano de 2019 o faturamento foi cerca de 2,84 vezes maior do que em 2018, totalizando R $\$ 147.785,00$ ao ano com 25 projetos. Em 2020, foi realizado 20 projetos que reverteram um faturamento anual de $\mathrm{R} \$ 188.145,00$, sendo $27,3 \%$ maior em relação ao ano anterior. A CJR encontra-se no Cluster 4 de maturidade das empresas juniores segundo o Sistema de Clusters da Brasil Júnior [Júnior 2019b]. Este sistema representa os níveis de maturidade em cada empresa júnior, parametrizando os clusters em uma escala de 1 a 5 , sendo 1 para empresas juniores menores e 5 para as mais consolidadas.

A CJR atualmente trabalha com o desenvolvimento de sistemas Web e aplicativos móveis, utilizando como principais tecnologias React JS e React Native, para frontend e Ruby on Rails para backend. Portanto, viabiliza uma capacitação técnica para seus integrantes, assim como desenvolve habilidades de liderança, comunicação, trabalho em equipe e proatividade.

\section{Participação Feminina na CJR}

Para a análise dos dados a respeito da participação das mulheres na CJR, a metodologia aplicada consistiu em uma coleta de dados dos seus associados, ao qual a própria empresa permitiu esse acesso. Foram coletados dados referentes ao gênero dos membros no período de 2018 a 2020, além da atuação por gênero em cargos de liderança. Infelizmente, não foi possível encontrar os dados anteriores a 2018 devido a alguns problemas que resultaram a perda desses registros pela empresa.

Em 2018, é possível observar na Figura 1 que houve a participação de 40 alunos, sendo 38 homens e somente 2 mulheres, ou seja, a participação feminina na CJR nesse ano era cerca de apenas 5\%. Já em 2019, pode-se notar uma pequena crescente, na qual essa participação sobe para 12,5\%, ou seja, entre 48 pessoas, 6 eram mulheres. Verificase que em 2020 houve um aumento no percentual de participação feminina, totalizando $23,5 \%$, assim sendo 1,88 vezes maior em comparação com o ano anterior. 
De acordo com o sistema acadêmico da instituição, a inserção feminina nos cursos do Departamento de Ciência da Computação da UnB nos anos de 2018 e 2019 foi 17,7\% e 13,79\% respectivamente. A presença de mulheres na CJR em 2018 foi muito menor do que a inserção feminina nos cursos de computação nesse ano, sendo de apenas $5 \%$. Em 2019, com 12,5\% de participação feminina na empresa júnior, houve uma aproximação da porcentagem nos próprios cursos de graduação do departamento. Em 2020, pôde-se notar uma crescente na CJR, chegando a ter em seu quadro $23,5 \%$ de participação feminina. Sendo assim, em 2020, tem em seus quadros 1,4 vezes mais mulheres que no ano de 2018 e 1,8 vezes mais do que em 2019. Essa diferença tem uma importância maior, uma vez que em 2020 não houve um aumento na participação das mulheres nos cursos de graduação em computação da Universidade de Brasília que continua com a média de $12 \%$ alunas de graduação.

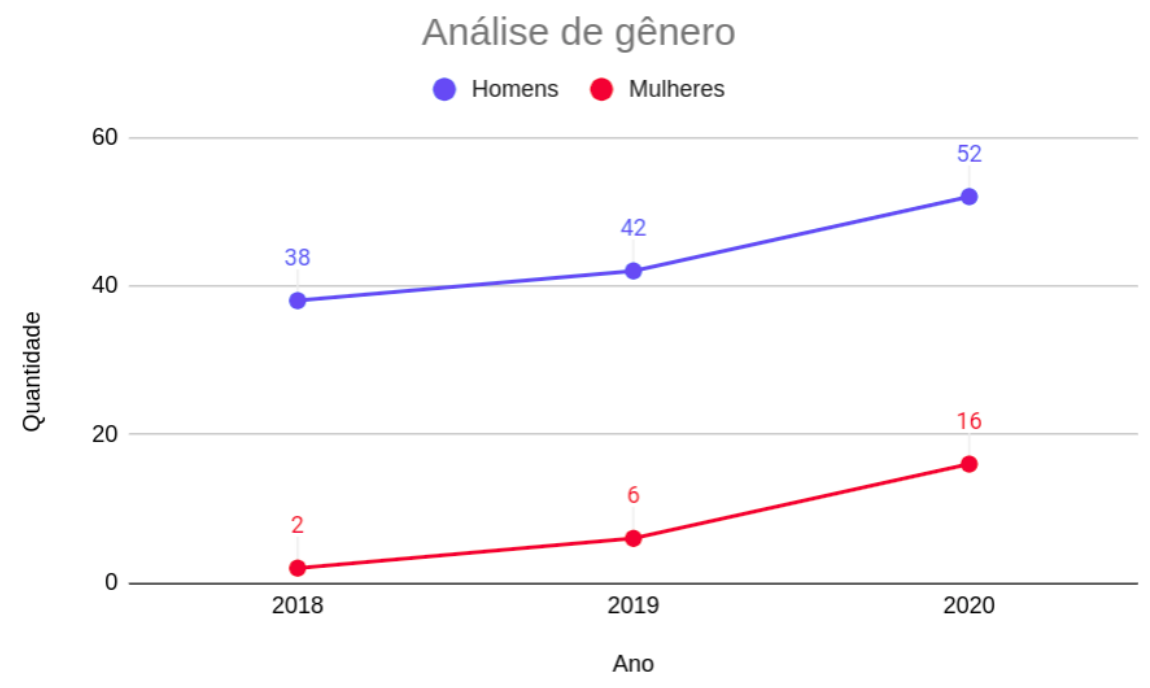

Figura 1. Participação por gênero na CJR.

\subsection{Análise da Participação Feminina em Cargos de Liderança}

Em 2018, o organograma organizacional da CJR era dividido em 5 núcleos. Consequentemente, a diretoria executiva da empresa era formada por 5 cargos de liderança, sendo estes: Presidente, Líder de Desenvolvimento e Pesquisa, Líder de Organização Empresarial, Líder de Talentos e Líder de Atendimento e Marketing. Dentre esses, pode ser observado na Figura 2 que havia somente 1 cargo ocupado por mulher, sendo esse o cargo de Presidente, e os outros 4 eram formados por homens.

Atualmente, a diretoria executiva da CJR é composta por 6 cargos, após o Núcleo de Atendimento e Marketing ter sido separado em dois núcleos em 2019. A liderança desse núcleo foi substituída pelos cargos de Líder de Atendimento e Vendas e Líder de Imagem e Publicidade. Assim, em 2019 infelizmente não houve participação feminina dentre os cargos de liderança, ou seja, 100\% dos cargos foram ocupados apenas por homens. Contudo, houve um aumento significativo em 2020, uma vez que a diretoria executiva passou a ter $50 \%$ de participação feminina, 3 de 6 cargos eram ocupados por mulheres. 


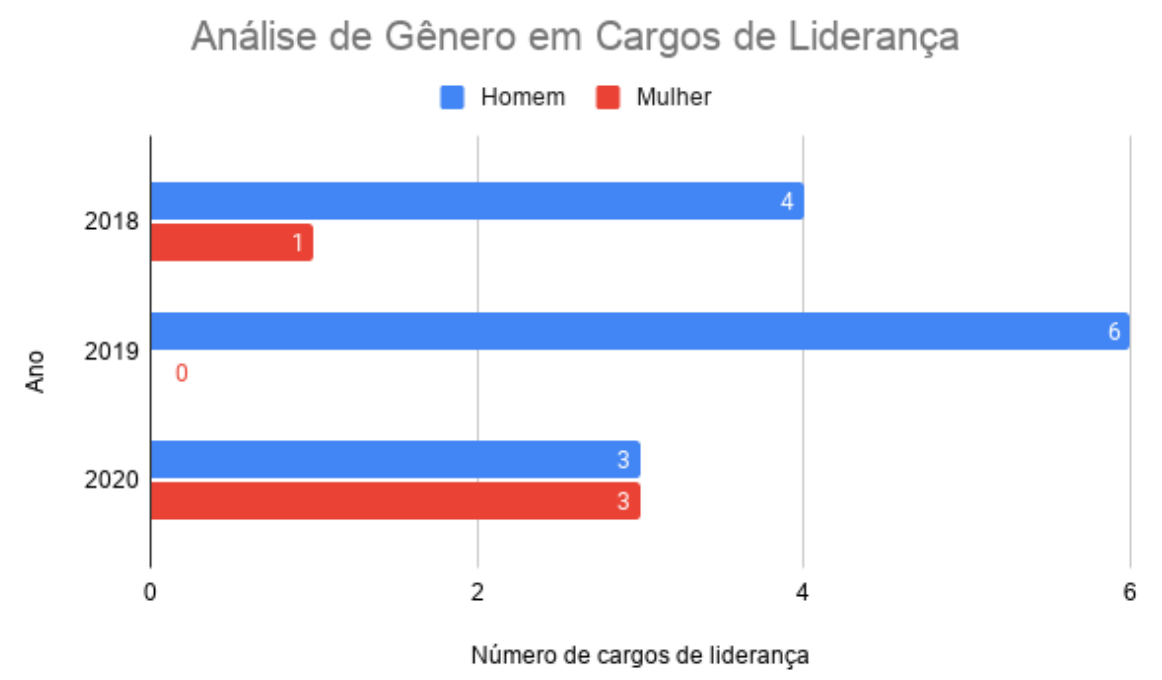

Figura 2. Participação por gênero em cargos de liderança na CJR.

\section{Ações para Inclusão de mais Meninas na CJR}

Na Empresa Júnior de Computação - CJR, o ingresso de trainees ocorre por meio de um Processo Seletivo (PS) realizado no início de cada semestre por meio de um formulário de inscrição. O Processo Seletivo compõe-se de três etapas: (1) entrevista individual; (2) dinâmica em grupo, que resulta na resolução de situações problemas; e (3) presença na palestra institucional para maior conhecimento da empresa. Os aprovados no PS seguem para o Processo Trainee onde são capacitados com as tecnologias utilizadas na empresa, e após esse processo são efetivados como membros da CJR.

Conforme analisado na seção anterior, haviam apenas duas meninas na empresa em 2018, em vista disso, o PS do segundo semestre de 2018, foi divulgado de uma forma mais atrativa para o público feminino. O tema desse Processo Seletivo foi Disney, com ênfase em personagens femininas fortes, independentes e inspiradoras para as meninas. Para a divulgação, foram distribuídos cartazes pelos espaços físicos da universidade, compostos geralmente por um personagem e uma frase inspiracional do filme adaptada para o contexto. Como por exemplo, um cartaz com a frase "Liberte o programador que há em você" e a personagem Mulan, fazendo alusão à trama da personagem no filme de mesmo nome. Um outro exemplo seria o cartaz com a personagem Moana e a frase "Quão longe você quer ir?", fazendo referência indireta à jornada da protagonista no filme.

Além de cartazes, houve também a divulgação através das mídias sociais, com publicações de imagens e tirinhas dentro dessa temática, informando que o PS está aberto. Nas mídias sociais foi utilizada uma linguagem adequada ao contexto desse meio de comunicação. Um exemplo de publicação seria uma tirinha na qual apresenta um diálogo entre princesas onde uma deseja fazer parte da CJR apesar de não ter experiência, mas as outras princesas a encorajam alegando que se tiver vontade de aprender já é perfeita para a empresa.

Ainda nesse Processo Seletivo, as candidatas foram entrevistadas pela própria presidente da empresa, com o objetivo de deixá-las mais confortáveis por serem entrevista- 
das por uma mulher. O gráfico da Figura 1, mostra que, em 2019 houve um aumento na inserção feminina, o que mostrou o impacto positivo de todas essas ações. Todos os processos seletivos seguintes tiveram esse cuidado de deixar as meninas menos desconfortáveis, sempre tendo ao menos uma mulher entrevistando as candidatas.

Nos anos seguintes, 2019 e 2020, além do cuidado nas entrevistas como citado anteriormente, houve a ação estratégica das meninas da empresa passarem nas salas de aula para a divulgação do PS, isso influenciou positivamente a quantidade de meninas inscritas. A equipe responsável pela aprovação dos candidatos do Processo Seletivo deu preferência a entrada de inscritos que contribuíssem para um aumento na diversidade dentro da empresa, incentivando candidatos LGBTQIA+, negros e mulheres. Consequentemente, houve um aumento de $11 \%$ na quantidade de meninas dentro da empresa.

Assim, além de se preocuparem com uma maior inserção de mulheres dentro da CJR, eles tiveram a sensibilidade de se atentarem a permanência das mesmas na empresa. Em vista disso, foram realizadas ações voltadas à criação de uma cultura organizacional mais inclusiva, proporcionando um ambiente mais acolhedor e respeitoso. Por exemplo, foram criadas ações de incentivo à cultura de feedback e uso de uma linguagem mais apropriada para uma comunicação agradável a todos.

\section{Importância da Participação das Alunas na CJR}

No intuito de entender melhor o impacto da participação das alunas na CJR, e as suas percepções em relação à questão de gênero na empresa, foi solicitado o depoimento de seis alunas, onde pelo menos duas dessas estiveram presentes em cada ano analisado. A Figura 3 apresenta uma nuvem com as palavras mais citadas nos depoimentos, na qual destacam-se "mulher", "menina", "mais", "não", "empresa" e "CJR". De maneira geral, essas palavras reportaram à importância de ter mais mulheres na empresa, da representatividade feminina, desde o processo de seleção e a própria permanência delas na CJR.

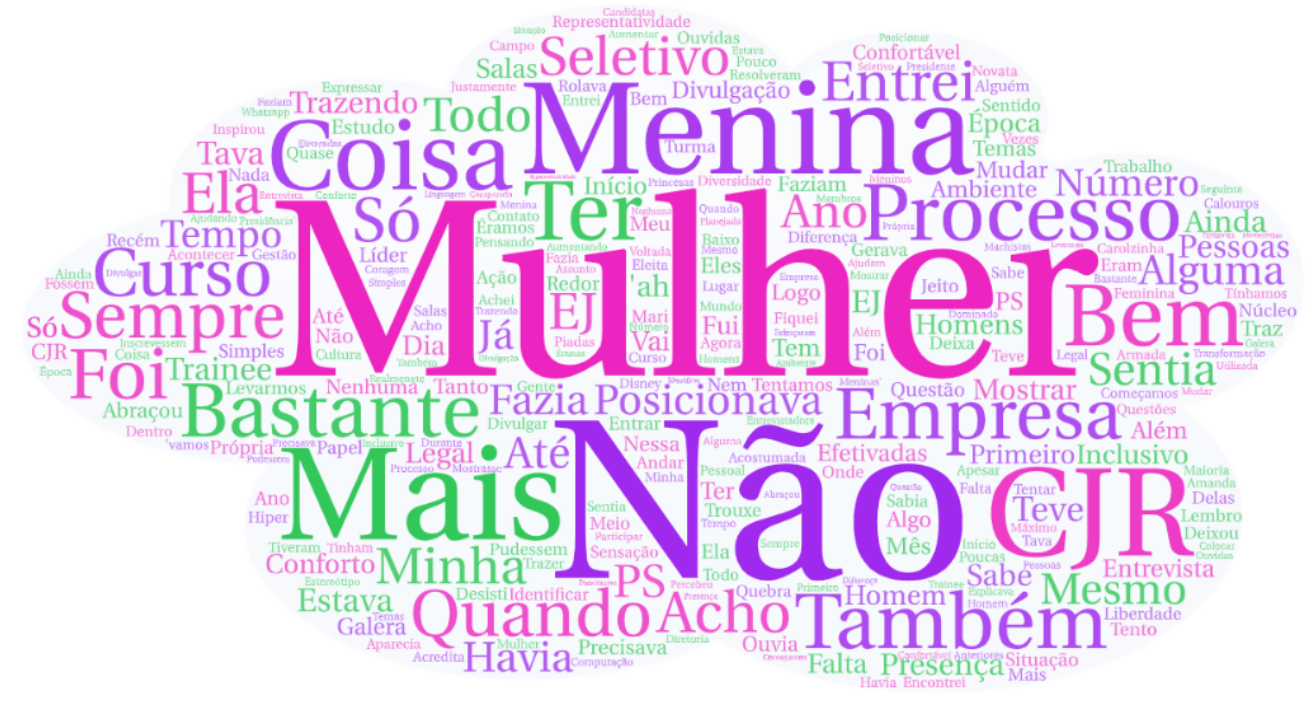

Figura 3. Nuvem de palavras dos depoimentos.

Após a leitura de todos os depoimentos, alguns trechos são apresentados a seguir. 
Todos os depoimentos apresentados possuem consentimento das participantes através da coleta do termo de consentimento livre e esclarecido (TCLE).

"No início, sentia muita falta da presença de mulheres, até porque no curso em si não havia muitas. Mas tentamos mudar essa situação com coisas simples e que faziam a diferença. Começamos com a própria divulgação do processo seletivo, trazendo temas inclusivos e que todos pudessem se identificar, além de levarmos as mulheres da EJ para divulgar o PS nas salas e mostrar que ali éramos ouvidas e tínhamos liberdade para nos expressar." Caroline Ferreira Pinto, membro da CJR em 2019 e Líder de Talentos em 2020.

"Quando eu entrei na CJR, eu me encontrei em um ambiente de estudo/trabalho com mais mulheres do que eu estava acostumada e isso me trouxe uma sensação de conforto... Eu lembro que mais diversidade na empresa era algo que eu ouvia bastante e, sempre que havia alguma divulgação da empresa para os calouros, alguma mulher também aparecia, por questões de representatividade, para mostrar que a CJR também acredita nessa quebra de estereótipo. A minha líder de núcleo também me inspirou bastante nesse sentido, era alguém que se posicionava, fazia acontecer e gerava transformação nas pessoas ao redor, tanto que algumas recém efetivadas desse ano resolveram entrar na empresa justamente porque tiveram contato com ela." Mayara Chew Marinho, membro da CJR em 2020 e Presidente da empresa em 2021.

"Quando eu entrei fiquei pensando de não ter meninas, mas logo na minha entrevista ter a Carolzinha (Caroline Ferreira) como entrevistadora me deixou mais confortável. Por isso, quando tem candidatas meninas tento participar das entrevistas delas. A presença feminina traz mais conforto. E deixa o ambiente mais inclusivo (apesar de que esse é, também, um papel dos homens na computação).” Priscila Angel Rodrigues Silva, membro da CJR em 2020 e 2021.

"Então, assim que eu entrei só tinha eu como mulher na turma de trainees e no primeiro dia eu quase desisti porque era o primeiro mês de curso e eu sabia que era um campo muito dominado por homem... eu não precisava andar armada dentro da CJR do jeito que eu precisava no curso. Ainda assim no whatsapp rolava umas piadas que as vezes eram meio machistas. Como menina novata eu não tinha coragem de me posicionar. Mas a Amanda (presidente em 2018) se posicionava. E ela se posicionava e explicava porque não era legal. E isso foi ajudando na cultura dos meninos da CJR.” Nayara Rossi Brito da Silva, membro da CJR nos anos de 2018, 2019 e 2020

"Era um lugar onde eu me sentia confortável, mesmo que a maioria dos membros fossem homens e eu sempre achei o máximo como as pessoas se ajudam na empresa. Na minha época o número de meninas estava aumentando. No meu processo trainee só tinha eu e a Mari de mulheres, e acho que mais 4 efetivadas na empresa. Era bem pouco... mas ainda era muito comparado aos anos anteriores e não tinha nenhuma mulher na gestão também. O pessoal percebeu que tinham poucas meninas na empresa e no processo seletivo seguinte eles se esforçaram bastante para que mais mulheres se inscrevessem." Clara Resende Maia, membro da CJR em 2019 e 2020.

"Quando eu fui eleita, uma das coisas que foi bem legal assim é que todo mundo abraçou muito essa questão 'ah agora a gente vai ter uma menina na presidência', é porque tinha bastante tempo que não tinha menina nem na diretoria assim sabe, porque 
realmenete o número de meninas tava bem baixo na CJR já tinha um tempo... Então acho que foi muito isso, não teve nenhuma ação hiper planejada assim, mas era um assunto que eu sempre tava trazendo e a galera da empresa abraçou muito isso essa questão de 'vamos aumentar o número de meninas' e representatividade. Na época o processo seletivo teve um que os memezinhos que a galera fazia que era das princesas da Disney, tentar trazer colocar mais coisas assim que mostrasse que a CJR era para menina também, sabe? Acho que durante muito tempo a linguagem mesmo utilizada não era nada voltada para as mulheres, era sempre uma coisa bem homem mesmo, assim." Amanda Oliveira Alves, Presidente da CJR em 2018.

Como é possível perceber nos relatos, após as iniciativas da CJR para melhorar o ambiente e aumentar a diversidade de gênero da organização, a mesma passou a ser um lugar onde a posição feminina passou a ser respeitada. Ter uma aluna como presidente foi colocado em diferentes depoimentos, e a representatividade ao mostrar que a empresa também era composta por alunas trouxe resultados, levando de $5 \%$ o número de alunas para $23 \%$ após as ações de inclusão.

\section{Conclusão}

Aumentar a diversidade de gênero na área de Computação é um desafio. Em cursos de graduação em Computação e no mercado trabalho o número de mulheres é bem menor que os dos homens. Essa é a realidade na Universidade de Brasília e também na CJR do Departamento de Ciência da Computação.

Para a inclusão de mais mulheres, como relatado neste artigo, a CJR criou ações de seleção para o público feminino, trabalhou internamente a questão do comportamento dos seus integrantes e aumentou a representatividade de meninas em suas apresentações. Como resultado, em 2020 houve um aumento no número de meninas na empresa e em cargos de gestão.

Como trabalho futuro, pretende-se acompanhar as alunas da Empresa Júnior de Computação - CJR durante o curso de graduação, assim como também no mercado de trabalho. Também, será realizada uma pesquisa com entrevistas com os fundadores da CJR para investigar como foi a inserção feminina na criação da empresa. Além disso, será feito um estudo sobre a inseção feminina em outras empresas juniores de computação existentes no Brasil, para analisar se outras empresas também se preocupam com a diversidade no seu ambiente de trabalho.

\section{Agradecimentos}

Agradecemos à CJR por disponibilizar os dados, às alunas que contribuiram com os seus depoimentos para esse artigo, assim como também, ao projeto Meninas.comp que trabalha para diminuir o gap de gênero no Departamento de Computação da UnB.

\section{Referências}

Ashcraft, C., McLain, B., and Eger, E. (2016). Women in tech: The facts. Workforce NCWIT Alliance.

Facebook (2020). Diversity report. https://diversity.fb.com/ read-report/. (Acesso em 20/02/2021). 
Google (2020). Google diversity annual report 2020. https://diversity . google/annual-report/. (Acesso em 20/02/2021).

Júnior, B. (2004). Conceito nacional de empresa júnior. https://silo. tips/download/conceito-nacional-de-empresa-junior. (Acesso em 20/02/2021).

Júnior, B. (2019a). Movimento empresa júnior. https://brasiljunior.org . br/conheca-o-mej. (Acesso em 20/02/2021).

Júnior, B. (2019b). Sistema de clusters. https://brasiljunior.org.br/ portal-da-transparencia. (Acesso em 08/03/2021).

Lanzillotti, R., Machado, G., and de Miranda, M. (2004). Empresa júnior: criação, divulgação e maturação. Revista Brasileira de Extensão Universitária, 2(2):110-113.

Pinheiro, T. B., Campolina, G. C. d. C., and Silva, A. L. (2019). Mulheres universitárias nas empresas juniores: perfil, perspectivas e dilemas na universidade federal de ouro preto. Revista de Administração da UEG.

Ribeiro, K., Azevedo, J., Maciel, C., and Bim, S. (2019). Uma análise de gênero a partir de dados da sociedade brasileira de computação. In Anais do XIII Women in Information Technology, pages 159-163. SBC.

Rosario, M. (2021). Lideranças femininas ganham espaço em empresas de tecnologia no brasil. https://veja.abril.com.br/brasil/ liderancas-femininas-ganham-espaco-em-empresas-del -tecnologia-no-brasil. (Acesso em 08/03/2021). 